\title{
AGRICULTURAL INFORMATION: NEW ZEALAND'S FORGOTTEN FUEL
}

\author{
P. N. TRIM
}

Management Services Division, MAF, Wellington

Abstract

The paper claims that we are still dealing with information in ways that were appropriate to the turn of the century. By 1988 we will not recognize the dimensions of the New Zealand produce information base. Information is the key to development and the retention of New Zealand's place in world markets. We must develop systems which are capable of coping with the needs of the future now or we shall be too late.

\section{INFORMATION}

It is on information that the future of New Zealand rests. There cannot be growth without it. We shall depend upon it to retain and improve our competitiveness on world markets. It is needed for increased production, perfected techniques, improved performance, wider diversification, wiser investment, and more intelligent selling and marketing.

\section{EXTENSION}

I believe we regard it as a medicine gained through training and experience which is ours to prescribe as we wish. I do not regard us as anything but conscientious. But what service. can this sort of dispensing give to our clients - the very people who have been charged with farming us through the decade?

What do each of us actually hold? It can be represented in two forms: what we have recorded - usually in the print medium and what is retained in our heads. Access to both is restricted. Very little of the total New Zealand produce related information is recorded in a way that is available to enquiry. Very little of the total is in a form which allows annotation and manipulation giving agricultural management the class of information it needs. 
How little is taken with us on to the farm. Worse yet, we can be accused of rejecting those ideas which are not in accord with our own.

No doubt you are aware of the characteristics of good information: Accuracy, relevance, timeliness, comprehensiveness, conciseness, with the correct confidentiality. Does the advice we give live up to these criteria? How can it? We cannot be aware of all the latest developments nor can we hold at our fingertips all the precise details of our trade. How about asking producers what they need? For many years they have tended to get what we have thought is good for them. Should we not let the market define our priorities for us?

How speedily and accurately do we respond to enquiry? I should like to draw to your attention our responsibility for the accuracy of what we impart. In the case Johnson versus the State of South Australia, the claimant charged state extension officers with negligence concerning the quality of their advice and was awarded $\$ 96613.63$ in damages.

Information is a commodity. It can be handled, packaged and sold. It can be designed to suit a variety of needs. It can look like news, like instruction, like legend, like just what you wanted. It can be interesting, stale or plain confusing. One thing is certain-it is not much good unless you can get it when you want it.

We are entering an age rich in information.

View-data will not be a toy but an investor's right arm. Think of it. Who is the best man? The man who gets information first and uses it.

Information is akin to energy. It does not come to us out of thin air, nor from a scientist's occasional brainstorm. Most information is distributed in its crude state all over the word. We search for it. We prospect for it. What we find we pass along human chains. The resourceful put it early into practice. Some, we say, are way ahead of their time. Scientists design trials, test it, and evaluate it against the potential needs of industry. This is the part that as New Zealanders we are good at. Trying things out.

We spend a great deal of our effort in generating information and very little in its dissemination - very little in any of the processes that are essential for easy access to a good quality product. We are poor at completing the information cycle. From the earth, through the refinery -we are good at that but we miss out on the systems, the pipelines that lead to improved farm practices - the completion of the cycle back to the farm - to the earth again. 
The processes which are vital if we are to satisfy future demand and if we are to fulfil what I claim to be our responsibility, are in giving enquirers what they need quickly-and everything they need.

What we need are effective pipelines, tankers and fuelling stations, that supply the energy for farm endeavour.

We are the ones who are responsible for future investment not the bankers or the businesses, because it is with good information that you put good money into good enterprises.

If information is energy, then we can illustrate our enterprise by an oil rig. It represents the gathering process, well designed and well constructed, built up in a way that will release the potential of the mine, more valuable than Maui or any field of subterranean oil, gas, coal or geothermal power.

\section{AGLINK INFORMATION SYSTEM}

The first step we estimate is the compilation of 7000 to 14000 titles covering all the consumers' needs as we understand them at present. Aglink, yes-that is the base. Add to it a retrieval system that makes these 14000 titles accessible. Then refine to a means for immediate delivery of a summary on any one, or a combination of these titles.

By 1988 we will not recognize the dimensioas of the New Zealand produce information base. To reach our 1985 target, which is to have at least 7000 titles completed and continually updated, means the incorporation of all the information which hitherto you may have seen as your personal property, but I have tried to persuade you belongs to New Zealand.

For ourselves, the Ministry of Agriculture and Fisheries has enlisted specialists in the field of information handling and communication in an effort to bring about this broad-based information service for the primary sector of the future.

This rig is the symbol. Let it symbolize a concept that you will find it your duty to support. We must record the information you hold in a systematic manner. New Zealand needs it. You have got it.

You cannot be satisfied with our present service any longer. To reach our 1985 targets we need you to start with us now.

Aglink will replace The Bulletin, the symbol of extension that was so highly effective seventy years ago. We do not farm the way we did in 1910, why are we satisfied with outmoded exten- 
sion methodology? Publication as a disseminator of information is yesterday's technique.

Aglink is the first major step to build a comprehensive reference system.

$$
\text { BIODATA }
$$

The final step is to develop a system that responds to all the various outlets and packages of the material in the most effective way for each target through each outlet. This is Biodata, the complete agricultural extension gathering, indexing, releasing and distributing system.

Cabinet has approved just over \$1 million for an Agriculture and Fisheries computer network.

It is our responsibility to match this decision by making the information we control freely available. Information is the key to development and the retention of New Zealand's place in world markets. 